This item was submitted to Loughborough's Research Repository by the author.

Items in Figshare are protected by copyright, with all rights reserved, unless otherwise indicated.

\title{
Experimental study of the performance and emissions characteristics of a small diesel genset operating in dual-fuel mode with three different primary fuels
}

\section{PLEASE CITE THE PUBLISHED VERSION}

http://www.sae.org/congress/2006/

\section{PUBLISHER}

(C) SAE International

\section{VERSION}

VoR (Version of Record)

\section{LICENCE}

CC BY-NC-ND 4.0

\section{REPOSITORY RECORD}

Patterson, Jill, Andrew Clarke, and Rui Chen. 2011. "Experimental Study of the Performance and Emissions Characteristics of a Small Diesel Genset Operating in Dual-fuel Mode with Three Different Primary Fuels". figshare. https://hdl.handle.net/2134/8409. 
This item was submitted to Loughborough's Institutional Repository (https://dspace.lboro.ac.uk/) by the author and is made available under the following Creative Commons Licence conditions.

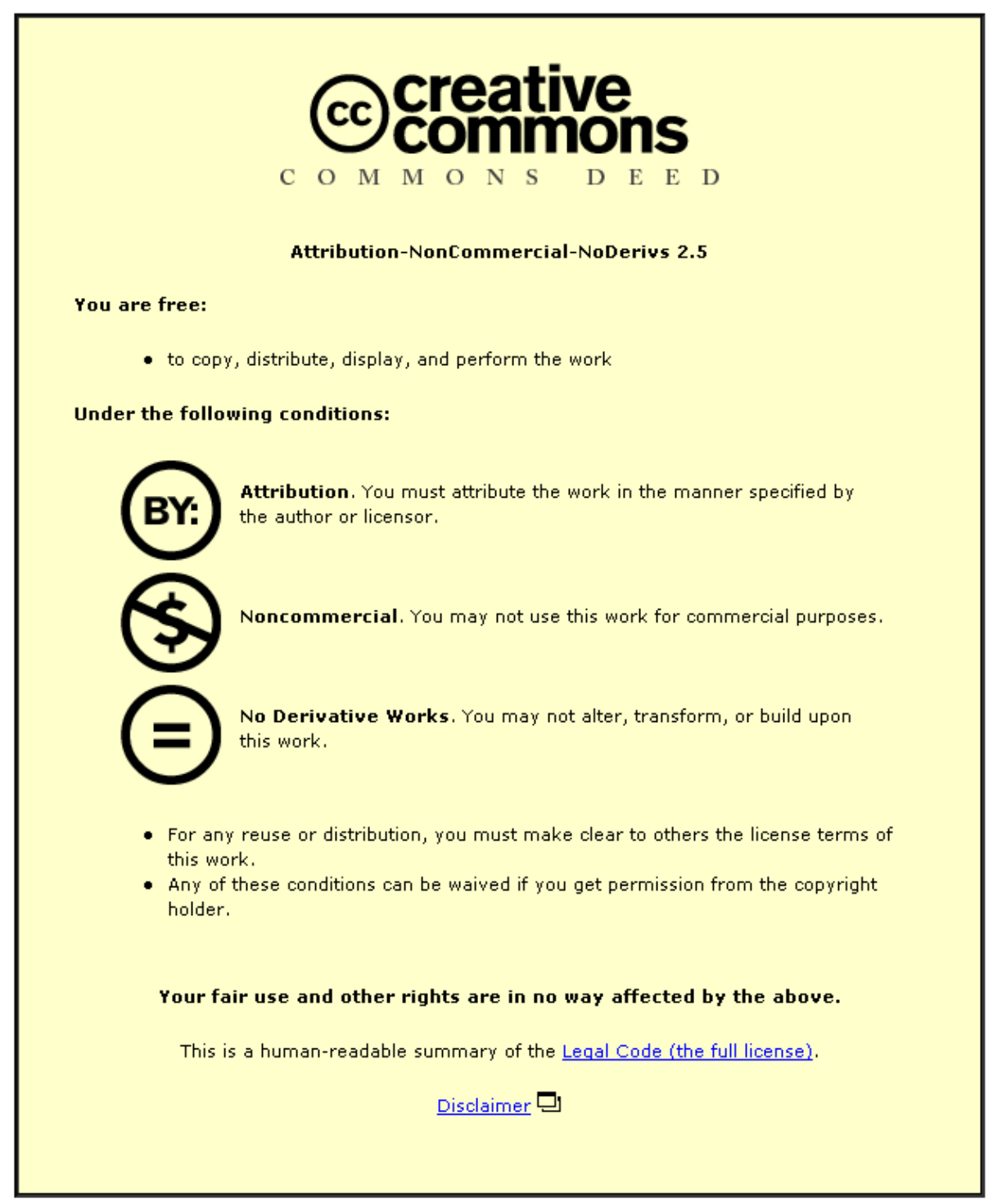

For the full text of this licence, please go to: http://creativecommons.org/licenses/by-nc-nd/2.5/ 


\section{Experimental Study of the Performance and Emissions Characteristics of a Small Diesel Genset Operating in Dual-Fuel Mode with Three Different Primary Fuels}

J. Patterson, A. Clarke and R. Chen Loughborough University, UK

Reprinted from: Emission: New Diesel Engines and Components and $\mathrm{CI}$ Engine Performance for Use with Alternative Fuels (SP-2014)

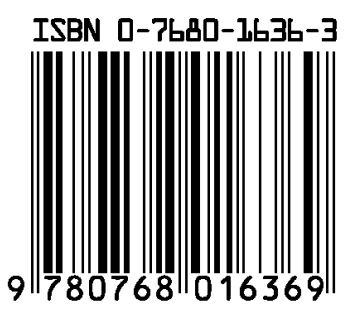


The Engineering Meetings Board has approved this paper for publication. It has successfully completed SAE's peer review process under the supervision of the session organizer. This process requires a minimum of three (3) reviews by industry experts.

All rights reserved. No part of this publication may be reproduced, stored in a retrieval system, or transmitted, in any form or by any means, electronic, mechanical, photocopying, recording, or otherwise, without the prior written permission of SAE.

For permission and licensing requests contact:

SAE Permissions
400 Commonwealth Drive
Warrendale, PA 15096-0001-USA
Email: permissions@ @ sae.org
Tel: $\quad 724-772-4028$
Fax: $\quad 724-776-3036$

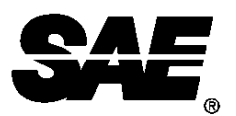

Global Mobility Database ${ }^{\circledR}$

All SAE papers, standards, and selected books are abstracted and indexed in the Global Mobility Database.

For multiple print copies contact:

\author{
SAE Customer Service \\ Tel: $\quad$ 877-606-7323 (inside USA and Canada) \\ Tel: $\quad$ 724-776-4970 (outside USA) \\ Fax: $\quad$ 724-776-0790 \\ Email: CustomerService@sae.org
}

\title{
ISSN 0148-7191
}

\section{Copyright $\odot 2006$ SAE International}

Positions and opinions advanced in this paper are those of the author(s) and not necessarily those of SAE. The author is solely responsible for the content of the paper. A process is available by which discussions will be printed with the paper if it is published in SAE Transactions.

Persons wishing to submit papers to be considered for presentation or publication by SAE should send the manuscript or a 300 word abstract to Secretary, Engineering Meetings Board, SAE.

\section{Printed in USA}




\title{
Experimental Study of the Performance and Emissions Characteristics of a Small Diesel Genset Operating in Dual- Fuel Mode with Three Different Primary Fuels
}

\author{
J. Patterson, A. Clarke and R. Chen \\ Loughborough University, UK
}

Copyright $\odot 2006$ SAE International

\begin{abstract}
A dual fuel engine is an internal combustion engine where the primary gaseous fuel source is pre-mixed with air as it enters the combustion chamber. This homogenous air fuel mixture is ignited by a small quantity of diesel known as the 'pilot' that is injected towards the end of the compression stroke. The diesel fuel ignites in the same way as in compression ignition (Cl) engines, and the gaseous fuel is consumed by flame propagation in a similar manner to spark ignited engines. The motivation to dual-fuel a $\mathrm{Cl}$ engine is partly economic due to the lower cost of the primary fuel, and partly environmental as some emissions characteristics are improved.
\end{abstract}

In the present study, a direct injection four cylinder $\mathrm{Cl}$ engine, typically used in genset applications, was fuelled with three different gaseous fuels; methane, propane and butane. The performance and emissions (NOx and smoke) characteristics of various gaseous concentrations were recorded at 1500rpm (synchronous speed) and at $1 / 4,1 / 2$, and $3 / 4$ load. In order to investigate the combustion performance under these different conditions, a three zone heat release rate analysis is proposed an applied to the data. The resulting mass burned rate, ignition delay and combustion duration are used to explain the emissions and performance characteristics of the engine. It will be shown that the highest gas substitution levels were achieved when using methane under all test conditions, but emissions of NOx and smoke were lower when using propane. Butane proved to be the most unsatisfactory of the three primary fuels, with the highest emissions of NOx and smoke.

\section{INTRODUCTION}

The term "dual fuel" refers to a $\mathrm{Cl}$ engine where a homogenous mixture of gaseous fuel and air is ingested, as in Otto cycle engines. The ignition source is the injection of a small quantity of diesel fuel, and the overall combustion process is similar to diesel cycle. The objective of this technique is to reduce problematic diesel engine emissions, particularly of NOx and smoke, but the drawback is that this reduction is often accompanied by an increase in emissions of $\mathrm{CO}$ and unburned hydrocarbons (UHC) [1]. A second benefit to using a gaseous fuel in a diesel engine is economic as the gaseous fuel can cost much less than the liquid fuel it replaces.

In light of proposed emissions legislation for non road diesel engines, this technology may be of interest. Although fixed speed generator engines are currently exempt from $97 / 68 / E C$, they will have to comply with tier III legislation from January $1^{\text {st }} 2007$. These requirements are that for engines up to $37 \mathrm{~kW}$ that $\mathrm{NOx}+\mathrm{HC}$ shall be reduced to $7.5 \mathrm{~g} / \mathrm{kWh}$ and particulate matter shall be reduced to $0.6 \mathrm{~g} / \mathrm{kWh}$. Dual fuel presents a method of achieving these reductions without the need for traps or reduction catalysts, provided that the combustion process can be optimized.

Karim [2], described the dual fuel combustion process as proceeding in three stages after ignition. The first stage is due to the combustion of around half of the pilot fuel and a small amount of gaseous fuel entrained within it. The second stage is due to diffusive combustion of the rest of the pilot and the rapid burning of gaseous fuel in the immediate surroundings. The third stage is due to flame propagation through the remainder of the gaseous fuel-air charge. This description of the combustion processes allows some explanation of the mechanisms of formation dual fuel exhaust emissions. For example, Karim et al. [3] found that oxides of nitrogen (NOx) formation is known to be strongly dependent on local temperatures and so most NOx would be formed in the region around the pilot spray where high temperatures exist and the equivalence ratio is close to stoichiometric.

Dual fuel engines typically use either natural gas/methane or LPG/propane as the primary fuel [4]. 
The performance of different gaseous fuels as compared with each other is the subject of this present research, as they have not been directly compared in modern DI diesel engine. Hence, analysis is made of performance and emissions characteristics obtained through varying pilot quantity and gaseous fuel concentration for three different fuels; methane, propane and butane, as these factors have been identified from a review of literature [57] as amongst the most important parameters influencing the dual fuel combustion process.

Methane, the main constituent of natural gas (typically $94 \%$ by volume in the UK), is preferred for use in dual fuel engines [8] as it is highly knock resistant and contains almost as much energy as other fuels, whilst fuel cost savings in using natural gas offset the cost of engine conversion. It is the simplest and most stable hydrocarbon and its gaseous nature allows the use of simple control systems leading to excellent mixing with air to provide more even charge distribution and smoother heat release rates [1]. Methane has a wide flammability range, low global toxicity (as compared to diesel) and has low photochemical reactivity [9]. Most of the UHC emissions in natural gas fuelled engines are methane, and although it is chemically resistant and toxicologically inert, it is does have 12 to 30 times the greenhouse effect of carbon dioxide and so requires control.

Propane is the main constituent of LPG, and is an attractive fuel for use in dual fuel engines as it is a single, relatively simple species so engines and after treatment systems and be designed to burn it cleanly [10]. It can be stored at atmospheric pressure so there are no evaporative losses. Propane has a good volumetric energy content and road octane number of more than 100. Consequently; it is considered that the most suitable use of LPG in engines is dual fuel rather than bi fuel [11]. Although propane is normally regarded as a fast reacting fuel, it has much extended ignition delays than with methane [12, 13], and although it tends to produce slightly higher power due to the fast burning rates, it is ultimately possible to achieve higher power outputs with the more knock resistant methane.

Butane is clean burning and a relatively simple fuel and has a greater volumetric energy content than propane alone and the emissions have a relatively low reactivity in the atmosphere [4]. Gota et al. [14] looked at the possibility of using butane in a low pollution, high efficiency dual fuel engine and found that when fuelled with butane, the engine had a higher thermal efficiency than when fuelled with propane, and much reduced quantities of diesel were needed for ignition. Almost the same output was achieved with butane as with pure diesel over a wide load range and without smoke, and dual fuel operation was satisfactory at idle with 70 percent of the total heating value being supplied by butane. The butane-diesel engine had the same specific fuel consumption and reduced NOx emissions were reduced as compared to diesel, however carbon monoxide (CO) levels were greatly increased. It was suggested that this effect was caused because butane acts as a reducing agent for NOx, but is itself oxidized to $\mathrm{CO}$. Propane and butane are by products of petroleum refining, and therefore are attractive fuels from an economic viewpoint.

\section{EXPERIMENTAL PROCEDURE}

\section{TEST FACILITY}

The present study focuses on the effect of concentration and type of gaseous fuel, and quantity of diesel pilot. In order to make direct comparisons between the various fuels and operating conditions, the inlet charge temperature and injection timing were fixed. The engine used in this study was a Lister-Petter inline four cylinder direct injection diesel engine, typically used in small diesel genset applications. Details of the engine specification are given in table 1.

\begin{tabular}{|l|l|}
\hline Engine Type & $\begin{array}{l}\text { Lister-Petter 4x90, DI, } \\
\text { 4stroke, naturally } \\
\text { aspirated diesel }\end{array}$ \\
\hline Configuration & Vertical in-line 4 cylinder \\
\hline Cylinder Bore x Stroke & $90 \times 90 \mathrm{~mm}$ \\
\hline $\begin{array}{l}\text { Connecting Rod } \\
\text { Length }\end{array}$ & $138 \mathrm{~mm}$ \\
\hline Compression Ratio & $18.5: 1$ \\
\hline Total displacement & 2.29 liters \\
\hline Rated Speed & $1800 \mathrm{rpm}$ \\
\hline Rated Power & $37.5 \mathrm{~kW}$ at 2100 rpm \\
\hline Fuel Injection Pump & Lucas Rotary \\
\hline
\end{tabular}

Table 1 -engine specifications

The engine was coupled to a Heenan-Dynamatic Mkll $220 \mathrm{~kW}$ eddy current dynamometer which controlled and measured torque and speed, with a maximum error in speed of $+/-1 \mathrm{rpm}$ and $+/-2 \mathrm{Nm}$ in torque. Intake airflow was measured using a laminar viscous flow air meter with a type 5 Cussons manometer. Inlet air depression was measured by a Druck type general purpose pressure transducer coupled to a digital readout. Various temperatures around the engine were measured via ' $K$ type' thermocouples for inlet air; cooling water before and after the cylinder head; exhaust gas, diesel and gaseous fuels. Diesel fuel consumption was recorded using a volumetric fuel measurement system. The installation is shown schematically in figure 1.

High-speed data, comprising of cylinder pressure, fuel line pressure and crank angle were acquired using a National Instruments PCIO-MX16-E PC-BNC rack interface coupled with a BNC 2090 capture board. Cylinder pressure was measured using a Kistler type 6053B60 piezocapacitive transducer connected to a Type 5011 charge amplifier. Fuel line pressure was obtained using a Kistler 4065A piezoresistive sensor and 4617A amplifier. This data was recorded at a resolution of 0.5 degrees crank angle on the falling edge of the crank degree marker signal from an AVL optical 
encoder, mounted directly on the engine crankshaft. The encoder also supplied a single pulse per revolution signal to mark top dead centre and trigger data acquisition of 50 consecutive four stroke cycles. Emissions measurements were obtained using an AVL 415 Variable Sampling Smoke Meter for smoke and a Horiba MEXA7100 HEGR exhaust gas analyzer system for NOx using a chemiluminescent method.

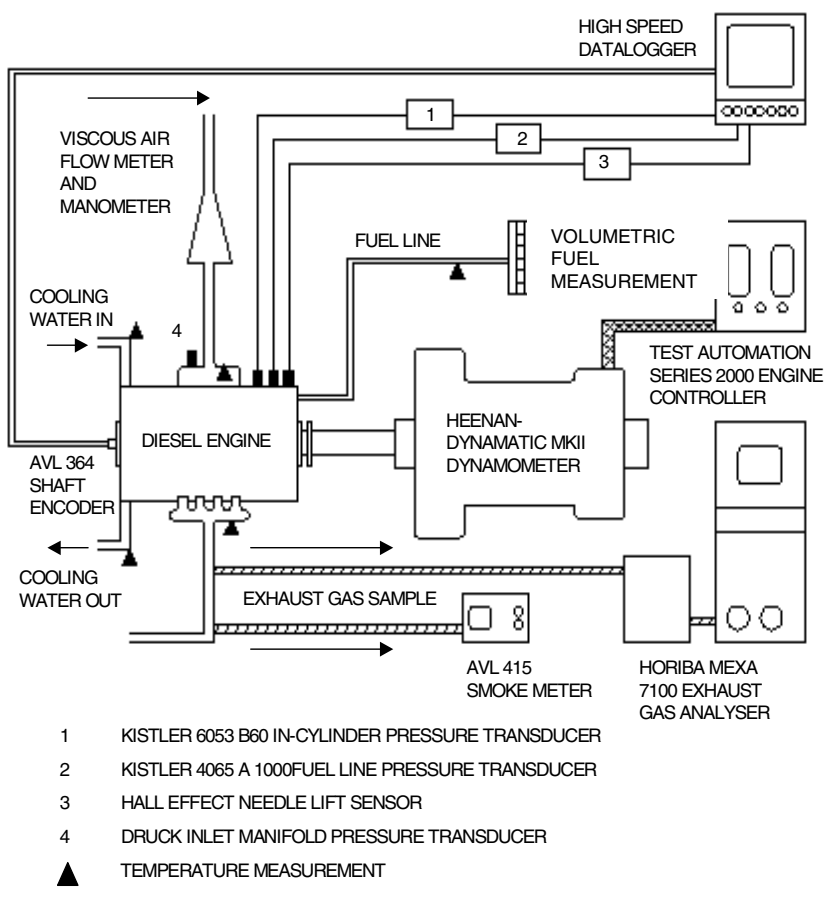

Figure 1 - Schematic diagram of the test engine and equipment

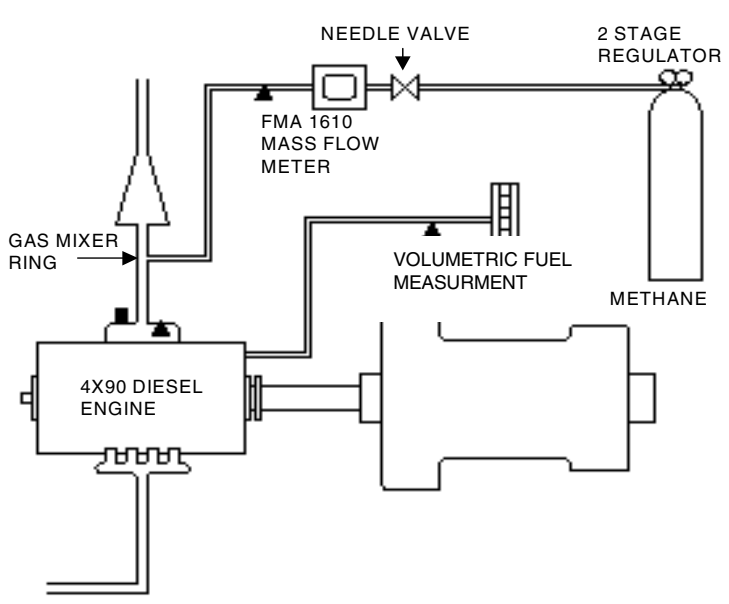

Figure 2 - Schematic of Gas Installation

\section{DUAL FUEL CONVERSION}

Turner and Weaver [15] concluded that a simple central point mixing system is the most inexpensive and straight forward method of admitting a gaseous fuel to the dual fuel engine, (although the penalty will be high emissions of UHC's). To this end, a simple venturi type gas mixer valve was installed at a distance of ten pipe diameters upstream of the inlet manifold to ensure complete mixing of the air and fuel were achieved before being inducted to the combustion chamber. Gaseous fuel flow rate was controlled by a needle valve located immediately upstream of an Omega FMA 1610 mass flow meter, which also recorded line pressure and gas temperature. The details of this gas supply system are shown schematically in figure 2 . The only other modification made to the engine was the replacement of the standard injectors with reduced flow injectors in order to improve injection performance.

\section{METHOD}

The engine used in this study is typical of engines used in small diesel genset applications between 20 and $60 \mathrm{kVA}$. The typical duty cycle of this type of engine is to operate for $90 \%$ of the time between $25 \%$ and $75 \%$ load. Therefore, engine performance and emissions data were obtained under steady state operating conditions at three loads corresponding to 1/4 load, 1/2 load and 3/4 load, and at $1500 \mathrm{rpm}$ (synchronous speed). To ensure repeatability and consistent operating conditions, the engine was first run for approximately 10 minutes at $1500 \mathrm{rpm}$ and $1 / 2$ load until the cooling water temperature out of the cylinder head reached $80^{\circ} \mathrm{C}$, and the exhaust gas temperature reached $250^{\circ} \mathrm{C}$. Once these conditions had been achieved, the engine was brought to the required test point, and allowed to settle there before sampling of data began.

\begin{tabular}{|l|c|c|c|c|}
\hline Fuels & Methane & Propane & Butane & Diesel \\
\hline $\begin{array}{l}\text { Chemical } \\
\text { Formula }\end{array}$ & $\mathrm{CH}_{4}$ & $\mathrm{C}_{3} \mathrm{H}_{8}$ & $\mathrm{C}_{4} \mathrm{H}_{10}$ & $\sim{\tilde{\mathrm{C}_{12}}}_{26} \mathrm{H}_{26}$ \\
\hline $\begin{array}{l}\text { Molecular } \\
\text { Weight }\end{array}$ & 16 & 44 & 58 & $\sim 170$ \\
\hline $\begin{array}{l}\text { Density at STP } \\
\left(\mathrm{kg} / \mathrm{m}^{3}\right)\end{array}$ & 0.647 & 1.779 & 2.345 & $\sim 840$ \\
\hline LHV (MJ/kg) & 50.05 & 46.33 & 45.73 & 42.9 \\
\hline Stoich Air/Fuel & 17.2 & 15.7 & 15.5 & 14.5 \\
\hline Cetane Number & $\sim 0$ & $\sim 0$ & $\sim 5$ & $40-55$ \\
\hline $\begin{array}{l}\text { Flammability U } \\
\text { Limits } \\
\text { (\% by volume of } \\
\text { gas in air) }\end{array}$ & 15.0 & 9.5 & 8.5 & 7.5 \\
\hline
\end{tabular}

Table 2 - Selected Properties of the gaseous fuels, Properties of diesel from ESSO Ultra Low Sulphur Diesel from Esso Marketing Technical Bulletin (ExxonMobil, 2001), Properties of gaseous fuels from manufacturers data sheets 
The first and last set of data to be acquired was for standard diesel No 2, (table 2). The first data set served as a baseline to which subsequent results could be compared, and the last data set confirmed that the results were repeatable, and that the engine performance had not been impaired by the use of gaseous fuels. Selected key properties for the gaseous fuels are also presented in table 2.

\section{HEAT RELEASE RATE ANALYSIS}

In order to optimize engine performance, an understanding of the processes occurring inside the combustion chamber is essential. Heat release analysis of in-cylinder pressure data is possibly the most widely used combustion diagnostic tool, and reveals information regarding the rate processes and combustion characteristics occurring inside the engine. In itself, heat release rate is strongly related to emissions characteristics, [16]. Emissions data provides some information about the combustion process, but additional information about the time development of thermodynamic variables are also required; thus heat release rate analysis remains a powerful investigative tool.

Heat release analysis is used here to investigate the dual fuel combustion process. The present contribution (based on [17]), consists of three control volumes, as this is conceptually close to dual fuel combustion where diesel is injected into an unburned zone, (made of air and a gaseous fuel) and eventually a burned zone is formed. This approach was also chosen because it allows a model for fuel injection derived from actual operating conditions to be used. The assumptions made are;

- The combustion chamber consists of a diesel fuel zone, and unburned zone and a burned zone, (denoted by the subscripts $f, u$ and $b$ respectively).

- The diesel zone refers to the diesel pilot only. Upon injection, the diesel fuel is assumed to instantly vaporize and obey the ideal gas law.

- The unburned zone into which fuel is injected is assumed to consist of air, exhaust gas residuals and a gaseous fuel (if present), in their measured proportions.

- The burned zone appears when combustion begins. Start of combustion is first determined from the point at which the first derivative of pressure with respect to time reaches a minimum value, and then confirmed by the second derivative of pressure being zero and the third being positive [18].

- Combustion is assumed to occur due to the entrainment of fuel and unburned gasses in stoichiometric proportion to air.
- Thermodynamic properties are assumed to vary in time, but not space. Individual species of the burned, unburned and vaporized fuel can be modeled as ideal gasses. Each zone has uniform temperature composition.

- Pressure is uniform across the combustion chamber.

The total mass in the combustion chamber consists of the mass of the trapped air, $\left(m_{0}\right)$ which is air and residual exhaust gasses $\left(m_{a}\right)$, and in the dual fuel case, a gaseous fuel $\left(\mathrm{m}_{\mathrm{g}}\right)$. The charge air and gaseous fuel proportions can be estimated from measured mass flow rates, and the residual gas fraction is assigned an arbitrary value [17] (as the gas exchange process is not simulated). Residual gasses were assumed to have the composition as described by Heywood [19]. After the start of fuel injection, the mass of the cylinder also includes the mass of the fuel injected. Therefore the conservation of mass in the cylinder at any instant can be expressed as

$$
\begin{gathered}
m=m_{u}+m_{b}+m_{f} \quad \text { where } \quad m=m_{o}+m_{f i} \\
\text { and } \quad m_{o}=m_{a}+m_{g}
\end{gathered}
$$

The rate at which the fuel flows from the fuel zone to the burned zone can be calculated by the difference between the mass of fuel injected at any instant $\left(\mathrm{m}_{\mathrm{fi}}\right)$ and the current mass in the fuel zone $\left(m_{f}\right)[17,20]$. For the dual fuel case there is the added complexity that the mass of the burned zone will also be a function of the mass of gaseous fuel that has been burned during each time step. In order to express this, it is assumed that combustion occurs at a stoichiometric air fuel ratio (AFRs) [3, 21, 22]. The AFRs has two hydrocarbon fuel components with molecular formulas of $\mathrm{C}_{\mathrm{xd}} \mathrm{H}_{\mathrm{xd}}$ and $\mathrm{C}_{\mathrm{xg}} \mathrm{H}_{\mathrm{g}}$; and the mass ratio of the two fuels is also known. The dual fuel stoichiometric fuel to air ratio is calculated as [23],

$$
\left(\frac{A}{F}\right)_{S, t o t}=\frac{\left(\alpha(x d+y d / 4)+\beta(x g+y g / 4) M W_{a i r}\right.}{\alpha\left(x d M W_{C}+y d M W_{H}\right)+\beta\left(x g M W_{C}+y g M W_{H}\right)}
$$

Where $\alpha=\frac{m_{d}}{m_{d}+m_{g}}$ and $\beta=\frac{m_{g}}{m_{d}+m_{g}}$

The mass of fuel burned is solved as part of the final equation set and therefore known. If the overall dual fuel AFR is maintained, then the mass of air entrained into the burned zone is given by:

$$
m_{b}=\left(m_{f i}-m_{f}\right)\left(1+A F R_{S, t o t}\right)+\left(m_{f i}-m_{f}\right)\left(\frac{\beta}{\alpha}\right)\left(1+A F R_{S, t o t}\right)
$$


Conservation of mass, ideal gas law and first law of thermodynamics are applied to each zone so that at any instant, there are twelve unknowns to be solved; the three masses $\left(m_{u}, m_{f}, m_{b}\right)$, the three volumes $\left(V_{u}, V_{f}\right.$, $\left.V_{b}\right)$, the three temperatures $\left(T_{u}, T_{f}, T_{b}\right)$, and the three internal energies $\left(u_{u}, u_{f}, u_{b}\right)$ of the zones. However, the system can be reduced to two ordinary differential equations and three algebraic equations with five unknowns. The differential equations are,

$$
\begin{aligned}
& \frac{d T_{u}}{d \theta}=\frac{d p}{d \theta} \frac{R_{u} T_{u}}{p c_{p u}}+\frac{d Q_{u}}{m_{u} c_{p u}} \\
& \frac{d T_{f}}{d \theta}=\frac{d p}{d \theta} \frac{R_{f} T_{f}}{p c_{p f}}+\frac{d m_{f} / d \theta\left(1 / 2 V_{i n j}^{2}\right)+d Q_{f} / d \theta}{m_{f} c_{p f}}
\end{aligned}
$$

The unknowns are $d T_{u}$ and $d T_{f}$, are solved by 4th Order Runge-Kutta method. Once $\mathrm{dT}_{\mathrm{u}}$ and $\mathrm{dT}_{\mathrm{f}}$ are known, $\mathrm{m}_{\mathrm{u}}$, $m_{f}$ and $T_{b}$ are found from three algebraic equations that are solved by Newton-Rhapson technique [24]:

$$
\begin{aligned}
f_{1}\left(m_{u}, m_{f}, T_{b}\right) & =m_{u}+m_{f+}\left(m_{f i}-m_{f}\right)\left(1+A F R_{s, t o t}\right) \\
& +\left(m_{g}-m_{u} \beta\right)\left(1+A F R_{s, t o t}\right)-m=0
\end{aligned}
$$

$$
\begin{aligned}
& f_{2}\left(m_{u}, m_{f}, T_{b}\right)= m_{u} R_{u} T_{u}+ \\
& m_{f} R_{f} T_{f}\left\{\left(m_{f i}-m_{f}\right)\left(1+A F R_{s, t o t}\right)\right. \\
&\left.+\left(m_{g}-m_{u} \beta\right)\left(1+A F R_{s, t o t}\right)\right\} R_{b} T_{b}-p V=0
\end{aligned}
$$

$$
\begin{aligned}
& f_{3}\left(m_{u}, m_{f}, T_{b}\right)=\left(m_{u} u_{u}+m_{f} u_{f}+R_{b} u_{b}\right. \\
& \left\{\left(m_{f i}-m_{f}\right)\left(1+A F R_{s, t o t}\right)+\left(m_{g}-\beta m_{u}\right)\left(1+A F R_{s, t o t}\right)\right\} \\
& -U_{0}-Q_{T}-m_{f i}\left(h_{f}+1 / 2 V_{i n j}^{2}\right)+W=0
\end{aligned}
$$

The main inputs to the model are a record of the cylinder pressure ( $p$ ) against crank angle $(\theta)$, and data for diesel fuel mass flow rate, needle lift, and fuel line pressure to determine the mass flow rate and injection velocity of the fuel. Other inputs required are the inlet temperatures and mass flow rates of the gaseous fuel and air, from which initial conditions at inlet valve closure and the mass fractions of gaseous fuel and air can be calculated. The engine speed is also required.

The mixture properties in the unburned zone are calculated from inlet valve closure to start of injection, using the initial conditions, pressure data and the ideal gas law. At start of injection the fuel zone comes into existence, and during the short ignition delay period, the reference conditions are added to the fuel and unburned zone, increasing the values of temperature, heat transfer $\left(d Q_{u}\right.$ and $\left.d Q_{f}\right)$ and internal energy.

The burned zone then appears at the start of combustion, and equations 5 to 9 are solved. In the case where a small pilot quantity is injected, the pilot may be completely consumed before combustion of the gaseous fuel is complete. A constraint is added here that if the mass of diesel becomes zero, the gaseous fuel will continue to burn in dual fuel mode, whereas in diesel mode, the combustion is complete and the gasses are expanded from that point. In this way, the turbulent flame propagation through the gaseous fuel zone can be implicitly included in the heat release analysis, if it is present. In order to implement this method, a record of the burned zone composition is preserved and used to calculate the new thermodynamic properties [25].

\section{RESULTS}

\section{RATE OF HEAT RELEASE}

The outputs from the three zone model that are analyzed are the mass burning rate per crank angle interval, ignition delay, and combustion duration. The mass burning rates are plotted for the three fuels in figures 4,5 and 6 . The graphs present data only for the extreme cases of minimum (10\%), propane maximum $(75 \%)$ and mid (50\%) energy substitution by gaseous fuel, although more substitution levels were considered in the analysis. It is worth noting that at all conditions examined here, although the three zone model analysis supports the concept of dual fuel combustion proceeding in three stages, the method tends to show the initial mass burning rates as having almost a step change between phase one and two. This is thought to be caused by the commonly applied assumption that the pilot and gaseous fuels burn in fixed proportions during the initial phase of combustion, and remains the subject of further research.

At $3 / 4$ load and gas substitution levels of $10 \%$ (lowest pane of figure 4), the mass burning patterns are similar in shape and magnitude for the three gaseous fuels as for diesel because there are only two stages in the combustion process; premixed and diffusion. For methane and propane, the magnitude and duration of the premixed phase of combustion was increased compared with diesel due to the entrainment of the gaseous fuel in the pilot spray. As propane has higher energy content than methane, the premixed combustion phase released more energy, and the pilot reaction zone was also increased, shown by the extended duration of the propane premixed phased. The diffusion burning phase was also slightly increased for methane and propane (compared with diesel), with propane exhibiting the highest mass burning rates. For $10 \%$ butane, the magnitude and duration of the premixed peak is reduced compared with diesel, but the diffusion burning phase shows much higher mass burning rates. These results suggest that for low gas substitution levels, dual fuel combustion of methane and propane occurs though their entrainment into the pilot fuel reacting zone and that 
there is no flame propagation, where as some (albeit small) degree of flame propagation is evident for butane.

For gas substitution levels of $50 \%$ (mid pane of figure 4), propane and butane show evidence of two separate phases in the premixed combustion process. Initially, the mass burning rate increases sharply, then slow before increasing to a 'premixed peak'. For all three fuels, this peak occurs earlier than for diesel, as the locally rich mixtures surrounding the pilot fuel promote faster initial combustion rates and higher temperatures. Consequently, the reaction zone is widened and more gaseous fuel is then burned in the second stage of combustion. Thus the premixed peak was much higher for methane and propane than for diesel. The diffusion burning period of $50 \%$ methane is reduced compared with diesel, which would suggest that temperature and gas concentration levels were not high enough to sustain flame propagation. The diffusion burning periods for propane and butane were much higher than for diesel. Butane exhibited almost equal rates of heat release in the two phases.
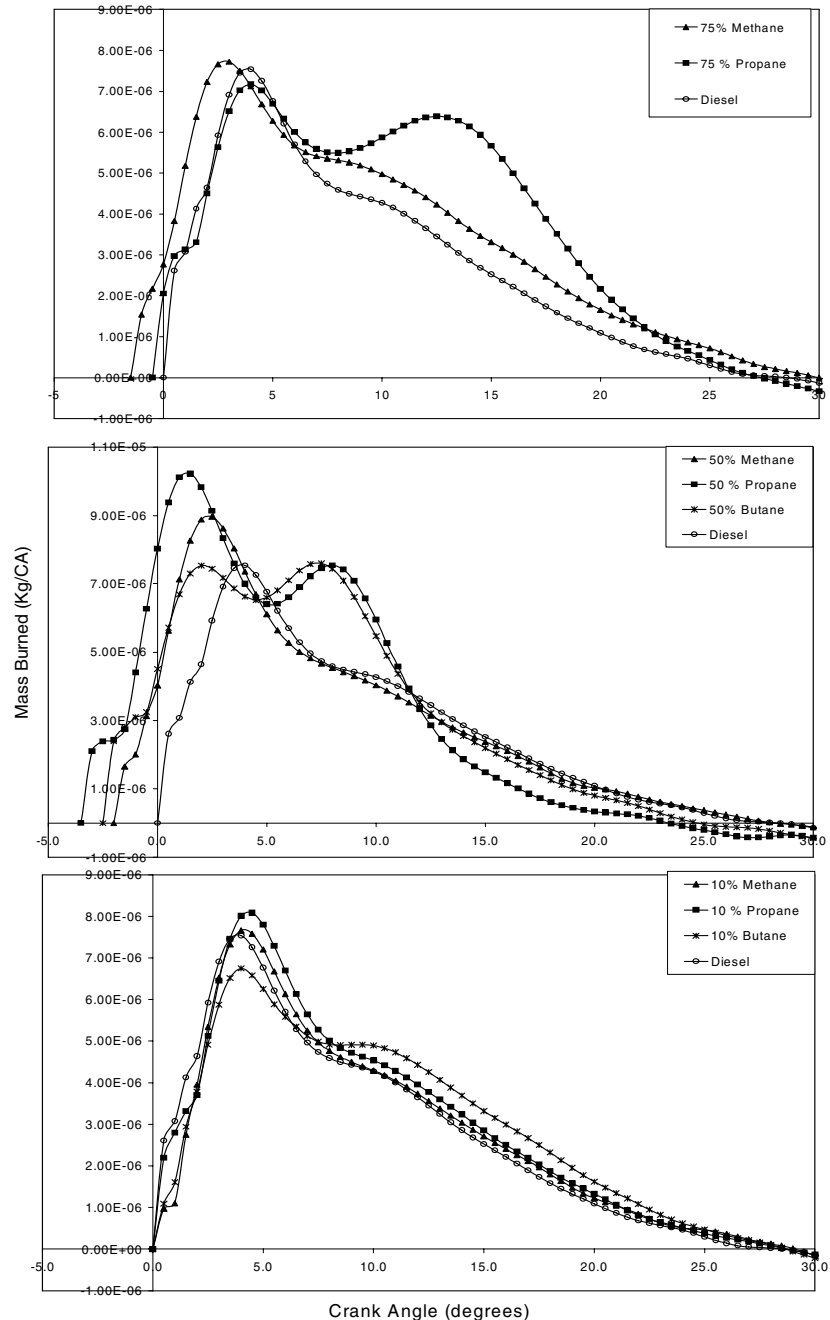

Figure 4 - Comparison of mass burning rates for the three fuels at $3 / 4$ load
$75 \%$ gas substitution levels (top pane of figure 4) were achieved only for methane and propane as severe engine knock limited maximum butane levels to $50 \%$. The premixed combustion phase of methane was slightly higher than for diesel, whereas for propane it was reduced. A greater mass burning rate can be observed for propane and methane compared with diesel.

The heat release rate analysis also shows that the combustion duration at first increases with the addition of gaseous fuel up to levels of $25 \%$. It then decreases with increasing gas up to $50 \%$, and then increases again. At $3 / 4$ load, the maximum gas substitution achieved was $50 \%$ for butane, $75 \%$ for propane and $85 \%$ for methane. (Maximum gas fuelling level was established on the basis of misfire at $1 / 4$ load, knock at $3 / 4$ load, or else when the engine fluctuations in speed and torque became too unstable for measurements to be taken.) For the $3 / 4$ load case, methane had the longest combustion durations and propane had the shortest durations.

The ignition delays were noted to be lowest for butane at all gas substitution levels, and the ignition delay was lower for butane than for diesel. Methane and propane exhibited almost the same values and trends as each other: at first, ignition delay remained the same as for diesel up to substitution levels of $25 \%$ and then ignition delay increased with increasing gas. Beyond $50 \%$ gas levels, ignition delay decreased again, but always remained higher than for diesel.

The results at $1 / 2$ load for the three fuels are plotted in figure 5 . For the $10 \%$ gas case (bottom pane of figure 5 ) the mass burning rate for all three gaseous fuel follows the same pattern as for diesel and there are only two stages evident in the combustion process. Methane has a slightly increased diffusion burning period, but an almost identical premixed phase to diesel. Propane has increased mass burning rates during both phases. The $10 \%$ butane case has reduced mass burning rates towards the end of the premixed phased and throughout the diffusion burning phase, but initial mass burning occurs earlier and more fuel is consumed at beginning of combustion.

At $50 \%$ gas substitution levels (middle pane of figure 5 ), both methane and propane exhibit earlier and significantly larger premixed combustion phases compared with diesel, and mass burning rates are slightly higher with propane throughout. For butane, the premixed peak is significantly reduced compared with diesel, even though combustion occurs earlier, and the diffusion burning phase dominates the combustion process.

The trends at $75 \%$ gas substitution (top pane of figure 5 ) are similar to those observed at $3 / 4$ load, but less pronounced. Methane still exhibits a larger premixed phase compared with diesel, and propane and butane have much reduced premixed phases and a greater rates of diffusion mass burning compared with diesel. 
The behavior of propane was the same as for the $3 / 4$ load case where combustion duration increased with gas levels of up to $25 \%$, then decreased before increasing again as gas substitution exceeded $50 \%$. Methane exhibited the same behavior pattern as for $1 / 4$ load where the addition of gaseous fuel up to $25 \%$ caused a decrease in combustion duration, but beyond $25 \%$ combustion duration increased. The combustion duration for butane at first increased (as for the $3 / 4$ load case), but then decreased. The longest combustion durations were recorded for butane up to substitution levels of $50 \%$, and beyond this point, methane exhibited the longest durations. At $1 / 2$ load, the maximum gas substitution levels that could be achieved were $75 \%$ for propane and butane, and $95 \%$ for methane.
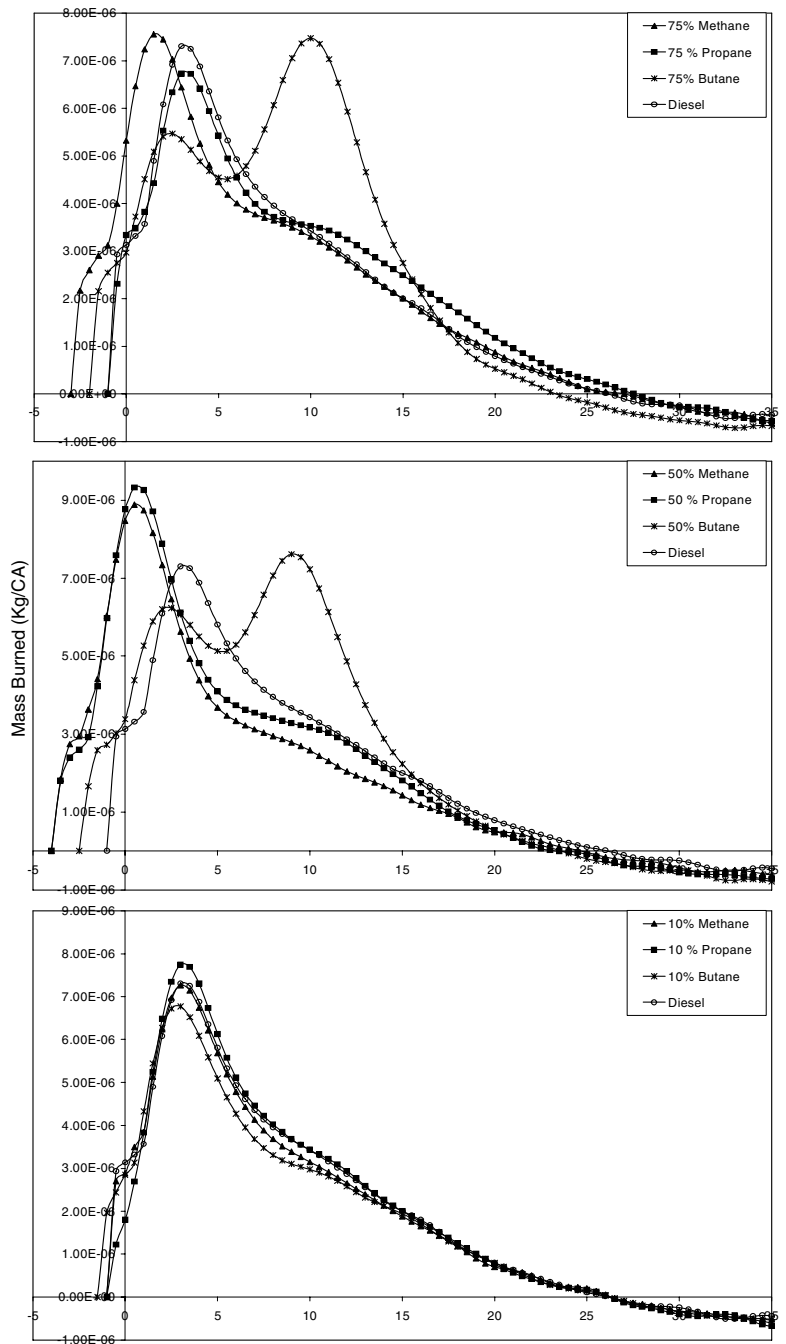

Crank Angle (degrees)

Figure 5 - Comparison of mass burning rates for the three fuels at $1 / 2$ load

As for the $3 / 4$ load case, butane exhibited the shortest ignition delays which were again lower than for diesel. This time, the longest ignition delays were recorded for propane and it can be seen that as the gaseous fuel concentration is increased, so are ignition delays.
Ignition delays for methane were slightly reduced as gas concentration was increased to $25 \%$, and then increased as methane concentration increased.
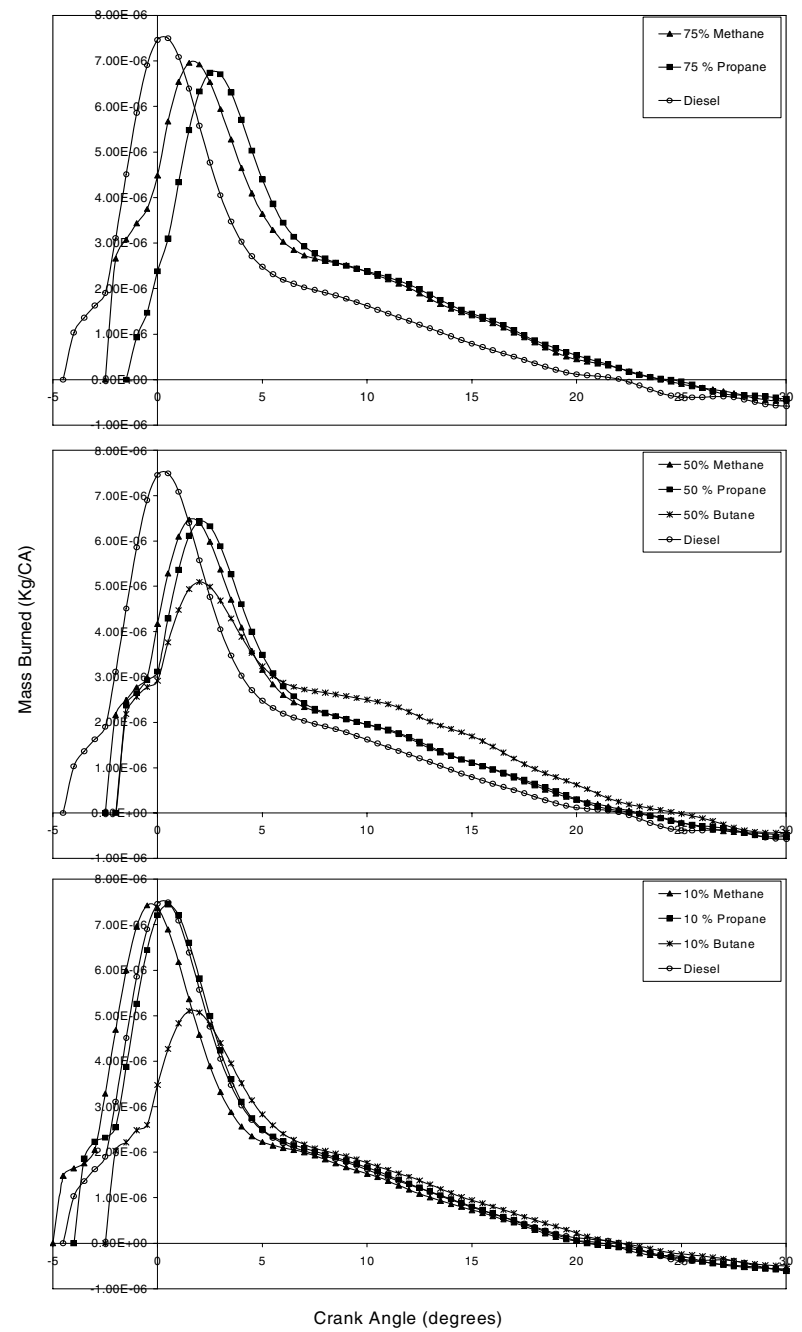

Figure 6 - Comparison of mass burning rates for the three fuels at $1 / 4$ load

Dual fuel combustion performance is known to be degraded at light load, which is illustrated by figure 6 . As the gas substitution level is increased, the premixed phase of combustion is greatly reduced for all three fuels compared with diesel, although the diffusion burning period increases slightly. Butane shows particularly poor combustion performance at low loads with very sluggish initial mass burning rates.

Overall, combustion duration decreases with load for all cases. At $1 / 4$ load the combustion duration at first decreased with gas substitution levels of up to $25 \%$ (bottom pane of figure 6). Combustion duration then increased as gas concentration increased for all fuels. The shortest combustion durations were recorded for propane and beyond $25 \%$ substitution levels methane exhibited the longest combustion durations. The maximum gas substitution levels that were obtained at $1 / 4$ 
load were $50 \%$ for butane, and $75 \%$ for methane and propane.

Methane ignition delays initially decreased with gas substitution levels of up to $10 \%$ and thereafter increased with propane again having longer ignition. For $1 / 4$ load, butane ignition delays remained approximately constant and at the same levels as for diesel. In all cases, as load decreased, ignition delay increased as might be expected.

\section{EMISSIONS}

NOX The emissions for NOx are normalized on a concentration basis against the base line diesel case, and are plotted against gas substitution level (the amount of energy normally provided by diesel that is replaced by the gaseous fuel) in figure 7 . It can be seen that at $1 / 4$ load (top pane of figure 7 ), that as the gaseous fuel concentration is increased, substantial reductions in NOx are achieved. At light load, NOx formation is strongly dependent on cylinder temperatures [26], and the addition of small amounts of a gaseous fuel (up to a stoichiometric mixture), increases ignition delay. This is because the preignition reactions of the gaseous fuel produce intermediate species that compete for radicals with the preignition reactions of the diesel fuel. The extended delay causes the pilot fuel to become more dispersed through the cylinder, and so the delayed combustion occurs at lower temperatures, thus causing a reduction in NOx. At $1 / 4$ load, most of the energy released in the dual fuel combustion system is due to the pilot and the gaseous fuel entrained within it. As the pilot becomes smaller, less of the gaseous fuel burns in the initial higher temperature phase of combustion. It is also likely that the reduced quantity of diesel fuel experiences poor atomization and penetration, which would also reduce the size of the reaction zone.

At $3 / 4$ load, (bottom pane of figure 7) the addition of a gaseous fuel causes an increase in NOx emissions up to substitution levels of approximately $60 \%$. This is because at high loads, high charge temperatures exist and the gradual reduction of the pilot quantity is mitigated by the increasing gas concentration and the net result has little effect on NOx. Beyond the $60 \%$ level, the addition of all gaseous fuels causes a large reduction in NOx. In this region, the high temperatures associated with the burning of the pilot affect less of the gaseous fuel, and most of the energy released is from the flame propagating at lower temperatures.

The trends at $1 / 2$ load are more complicated, (mid pane of figure 7). At first, the addition of small quantities of gas cause the emissions of NOx to decrease slightly, but they then increase at $50 \%$ substitution levels before decreasing more dramatically at higher gas concentrations. This is because the addition of small quantities of the gas at first increases the ignition delay and hence lowers combustion temperatures, which would result in reduced NOx. As the concentration of gas then approaches the lean flammability region, the flame can propagate through most of the combustion chamber, and the pilot is still large enough to affect most of the charge, thus leading to higher temperatures. Eventually, the pilot size and reaction zone decrease and more of the energy release is from flame propagation. The lower temperatures combined with a richer mixture and less oxygen and nitrogen combine to reduce NOx.

It can also be seen that the emissions of NOx from propane are lower than for methane. This is because propane is much more reactive than methane and tends to produce more intermediate species during compression that impede the pre-ignition reactions of diesel. The emissions of NOx were highest for butane, which would also be expected as butane has the highest flame temperatures of the fuel, and the greatest energy content. The results also suggest that the addition of a small quantity of methane or propane has a beneficial effect in reducing NOx emissions at $1 / 4$ and $1 / 2$ load.

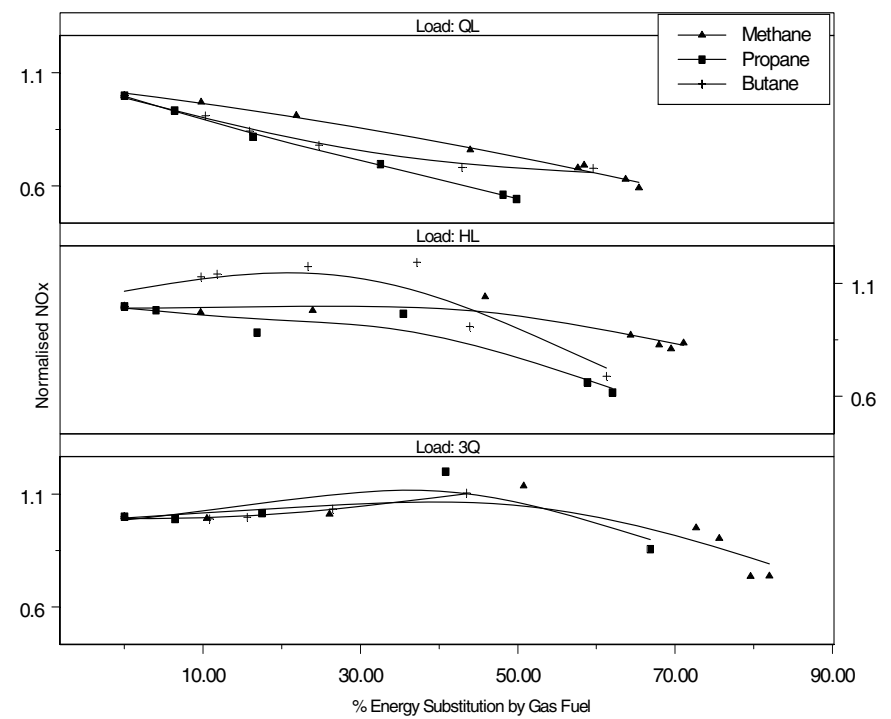

Figure 7 - Variation of NOx with different fuels at different loads

SMOKE

Figure 8 shows that for all three gaseous fuels, smoke was increasingly reduced by the addition of a gaseous fuel. It can be seen that, as the proportion of gaseous fuel is increased, the smoke decreases. This would be expected as gaseous fuels contain no heavy hydrocarbons. Again, the reductions with propane were higher than for methane, and smoke was virtually eliminated at $3 / 4$ load (bottom pane of figure 7). The emissions of smoke were recorded using an AVL smoke meter, and so it is important to note that whilst the visible smoke was clearly reduced, there was no way of recording what happened to the ultrafines.

The reductions with butane were the least impressive, and initially, for $1 / 4$ and $1 / 2$ load, emissions of smoke increased with the addition of butane. This was probably due to locally very rich mixtures with the addition of small quantities of butane. 


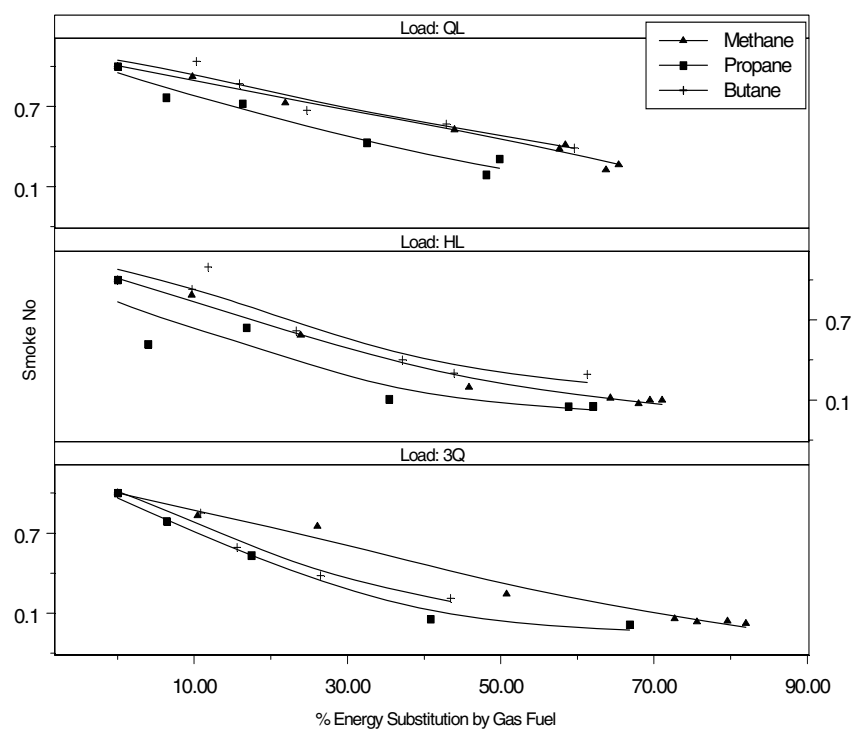

Figure 8 - Variation of AVL smoke number with increasing gas substitution levels (\%) for the different load conditions and fuels

\section{DISCUSSION}

\section{COMBUSTION PERFORMANCE}

From the results of the three zone model, it would appear that in addition to their being three stages in the dual fuel combustion process, there are also three different combustion patterns that occur. The first pattern is observed at low gas substitution levels where the combustion process closely mirrors the diesel baseline (shown by the bottom pane of figures 4,5 and 6). At the highest gas substitution levels, the pilot fuel is purely an ignition source and the premixed phase is significantly reduced so combustion pattern is dominated by diffusion combustion and flame propagation (top panes of figures 4,5 and 6). In between these two phases there is a region where premixed combustion and diffusion burning can make an almost equal contribution, the relative size of each zone depends on initial combustion rates (primarily a function of the pilot combustion). This transition regime is also characterized by having shorter ignition delays and shorter combustion durations, and because combustion temperatures are high, NOx emissions are also higher. The transition between the three regimes occurs at lower gas substitution levels when a more reactive gaseous fuel is used, and also occurs earlier when the reactivity of the gaseous fuel is promoted (such as at the elevated temperature and pressures occurring at higher loads).

\section{QUANTITY OF PILOT}

At light loads and hence lean mixtures, the pilot fuel quantity is the most important variable influencing engine emissions and performance. Most of the energy release is from the combustion of the pilot and entrained gaseous fuel, and there is little contribution from the rest of the charge. The larger pilot has a larger reaction zone and the volume of the charge affected by pilot combustion is increased. At higher loads where the concentration of gaseous fuel is above the lean flammability limit, or for more reactive gaseous fuels, (i.e. where flame propagation occurs), changing the pilot quantity has little effect.

When the pilot quantity is reduced, the amount of fuel prepared for burning during the ignition delay decreases, and the amount of gas entrained by the pilot decreases. At $1 / 4$ load, these two factors result in a weaker ignition source leading to sluggish combustion and a latter occurrence of peak cylinder pressure. During the increased ignition delay, the small quantity of diesel fuel may be increasingly dispersed and this further weakens the gaseous fuel-air ignition. [27]. A useful strategy to improve poor combustion at light loads is to increase the pilot quantity to improve injection characteristics leading to more stable combustion without misfire [28].

The emissions trends of NOx correlate with the three different combustion patterns that can occur. At conditions where the combustion pattern is similar to diesel, the NOx emissions are highest, and where the classic dual fuel combustion pattern is observed, NOx emissions are lowest. There is a tendency for NOx emissions to increase where the combustion pattern is transitional between the two cases as initial cylinder temperatures are high during the premixed phase, and remain high during diffusion burning. The influence of the initial rates of premixed heat release are most important in this transition regime - if they cause the premixed peak to be higher then NOx emissions will also be higher.

\section{CONCENTRATION OF GASEOUS FUEL}

In dual fuel engines the combustion and emissions characteristics are strongly dependent on the type and concentration of the gaseous fuel, and the gas substitution levels are particularly important at higher loads. This is because the pre-mixed charge is subjected to increasing temperatures during compression causing the pre-ignition activity to progress substantially. Increased reaction activity raises the charge temperature, which slightly compensates for the drop in temperature that addition of a gaseous fuel tends to cause [29]. The intermediates species from these reactions such as radicals, aldehydes and $\mathrm{CO}$ are produced in significant amounts towards the end of compression where they directly influence the preignition processes of the pilot, and consequently all subsequent features of the combustion processes [12].

Combustion of the pilot fuel directly contributes to the combustion of the entrained gaseous fuel, but turbulent flame propagation will not occur until the concentration of gaseous fuel is beyond a limiting value. This value is reached earlier for higher loads and more reactive gaseous fuels. Beyond this point, there is a marked 
increase in the gaseous fuel's contribution to energy release.

At low load and higher gas substitution levels, most of the energy release comes from the pilot fuel, the entrained gaseous fuel, and gas in the immediate vicinity of the pilot. Relatively little of the energy release comes from the gaseous fuel air charge further away from the pilot as consistent flame propagation from the ignition centers does not take place [2].

Smoke reductions are primarily a function of the gaseous fuel type and concentration; greater reduction in pilot quantity and hence heavy hydrocarbons result in lower emissions of visible smoke. Smoke was also lowest for propane at all load and substitution levels, except when the maximum methane substitution exceeds propane. This is because the combustion pattern of methane tended to follow diesel to much higher substitution levels, and the higher premixed peak lead to higher smoke. Propane always tended to have a longer diffusion burning period, and so more smoke was oxidized. Butane had the shortest diffusion period of the three gaseous fuels and also tended to have high smoke levels.

\section{CONCLUSION}

The three zone model has identified that three different combustion patterns occur as the concentration of gaseous fuel is increased. At low gas substitution levels, the combustion pattern closely follows diesel, and at high substitution levels the classic three stage dual fuel combustion process appears. In between the two regimes there is a transition region where, depending on initial rates of heat release, the premixed and diffusion periods make an equal contribution. The change from one regime to another occurs earlier when the gaseous fuel is more reactive.

NOx emissions correlate more closely to the changing combustion patterns, and smoke emissions are more a function of gaseous fuel substitution levels. Of the three gaseous fuels, propane exhibited the best emissions performance, as the combustion pattern changes more quickly from diesel to classic dual fuel, and the diffusion burning period was also the longest.

The transition region between the diesel and classic dual fuel combustion patterns offers no benefits in terms of emissions reduction.

\section{NOMENCLATURE}

$\mathrm{AFR}_{\mathbf{s}}$ Stoichiometric air to fuel ratio

$A F R_{s, t o t}$ Stoichiometric air to fuel ratio of two fuels

$\mathrm{m} \quad$ mass $(\mathrm{kg})$

R gas constant ( $/ \mathrm{kgK})$

$\mathrm{p} \quad$ cylinder pressure $(\mathrm{Pa})$

Cp specific heat at constant pressure $(\mathrm{J} / \mathrm{kgK})$

$\cup \quad$ total internal energy $(J)$ u specific internal energy $(\mathrm{J} / \mathrm{kg})$

h $\quad$ specific enthalpy $(\mathrm{J} / \mathrm{kg})$

Q heat transfer $(\mathrm{J})$

W work (J)

$\alpha \quad$ diesel mass fraction of fuels

$\beta \quad$ gaseous fuel mass fraction of fuels

$\theta \quad$ crank angle degrees

\section{Subscripts}

u unburned zone

f diesel fuel zone

b burned zone

o reference condition

$\mathrm{fi}$ fuel injected to date

a air

g gaseous fuel

\section{REFERENCES}

1. Karim, G.A., The Dual Fuel Engine of the Compression Ignition Type - Prospects, Problems and Solutions - A Review, SAE 831073:(1983).

2. Karim, G.A., Combustion in Gas Fuelled Compression-Ignition Engines, ASME ICE Fall Technical Conference. 351:(2000).

3. Kishnan, S.R., M. Biruduganti, Y. Mo, S.R. Bell, and K.C. Midkiff, Performance and Heat Release Analysis of a Pilot-Ignited Natural Gas Engine, IMechE:(2002).

4. Patil, P.G., Alternative Fuels in Future Vehicles, Automotive Engineering. 1041:(1996).

5. Gebert, K., N.J. Beck, R.L. Barkhimer, and H.C. Wong, Strategies to Improve Combustion and Emission Characteristics of Dual-Fuel Pilot Ignited Natural Gas Engines, SAE 971712:(1997).

6. Lin, Z. and W. Su, A Study on the Determination of the Amount of Pilot Injection and Rich and Lean Boundaries of the Pre-Mixed CNG/Air Mixture for CNG/Diesel Dual-Fuel Engine, SAE. 2003-010765:(2003).

7. Mbarawa, M., B.E. Milton, and R.T. Casey, An investigation of the effects of diesel pilot injection parameters on natural gas combustion under diesel conditions, Journal of the Institute of Energy. September 200174:(2001).

8. Park, T., R.J. Atkinson, N.N. Clark, M.L. Traver, and C.M. Atkinson, Operation of a Compression Ignition Engine with a HEUI Injection Sysetem on Natural Gas with Diesel Pilot Injection, Alternative Fuels. SAE199901-3522:(1999).

9. Liu, B., M.D. Checkel, R.E. Hayes, M. Zheng, and E. Mirosh, Experimental and Modelling Study of Variable Cycle Time for a Reversing Flow Catalytic Conductor for Natural Gas/Diesel Dual Fuel Engines, Exhaust Aftertreatment Modelling and Gasoline Injection Aftertreatment. SAE 2000-01-0213:(2000).

10. Newkirk, M.S., L.R. Smith, M.L. Payne, and J.S. Seagal, Emissions with butane/propane blends, Automotive Engineering. 10411:(1996).

11. Pirouzpanah, V. and A.B. Nohammadi, DualFuelling of an Industrial Indirect Injection Diesel Engine by Diesel and Liquid Petroleum Gas, International Journal of Energy Research. 20:(1996). 
12. Karim, G.A. and A. Rogers, Comparative studies of propane and butane as dual-fuel engine fuels, Journal of the Institute of Fuel. 40322:(1967).

13. Liu, Z. and G.A. Karim, The Ignition Delay Period in Dual Fuel Engines, SAE 950466:(1995).

14. Goto, S., H. Furutani, M. Komori, and M. Yagi, LPG-Diesel Engine, International Journal of Vehicle Design. 153/4/5:(1994).

15. Turner, S.H. and C.S. Weaver, Dual-Fuel Natural Gas/Diesel Engines:Technology, Performance, and Emissions. (1994), Gas Research Institute. p. 83. 16. Bruntt, M.F.J. and K.C. Platts, Calculation of Heat Release in Direct Injection Diesel Engines, SAE, 1999-01-0187:(1999).

17. Sastry, G.V.J. and H. Chandra, A Three-Zone Heat Release Model for DI Diesel Engines, SAE. 940671:(1994).

18. Stone, R., Introduction to Internal Combustion Engines, Macmillan Press Ltd. (1999)

19. Heywood, J.B., Internal Combustion Engine Fundamentals, McGraw-Hill. (1988). p. 930.

20. Timoney, D.J., C.P. McNally, and C.T. Doyle, $A$ Three-Zone Heat Release Model for Direct Injection Diesel Engines, Theisel. 2000:(2000).

21. Khan, M.O., Dual-Fuel Combustion Phenomena, in Department of Mechanical Engineering. (1969), Imperial College of Science and Technology: London. p. 289.

22. Pirouzpanah, V. and K. Amiraslani. A model to predict performance and heat release of dual-fuel diesel engines. in Symposium on Gas Engines and CoGeneration. 1990. Solihull: MEP.

23. Liu, Z. and G.A. Karim, Simulation of combustion processes in gas-fuelled diesel engines, Proceedings of the Institute of Mechanical Engineers. 211A:(1997).

24. Press, W.H., S.A. Teukolsky, W.T. Vetterling, and B.P. Flannery, Numerical Recipes in Fortran 77: The Art of Scientific Computing, Cambridge University Press. (1992)

25. Olikara, C. and G.L. Borman, A Computer Program for Calculating Properties of Equilibrium Combustion with Some Applications to I.C. Engines, SAE, 750468:(1975).

26. Karim, G.A., Z. Liu, and W. Jones, Exhaust Emissions from Dual Fuel Engines at Light Load, SAE, 932822:(1993).

27. Poonia, M.P., A. Ramesh, and R.R. Gaur, Effect of Intake Temperature and Pilot Fuel Quantity on the Engine Combustion Characteristics of a LPG Diesel Dual Fuel Engine, Alternative Fuels. SAE 982455:(1998).

28. Karim, G.A., Z. Liu, and W. Jones, Exhaust Emissions from Dual Fuel Engines at Light Load, SAE 932822:(1993).

29. Karim, G.A., W. Jones, and R.R. Raine, An Examination of the Ignition Delay Period in Dual Fuel Engines, SAE, 892140:(1989). 